\title{
RELAÇõES ENTRE INSTITUIÇõES PÚBLICAS E PRIVADAS NA GERAÇÃO DE DESENVOLVIMENTO SUSTENTÁVEL: potencialidades e limitações da região do Alto Paranaíba - MG.
}

\author{
1- Fabiana Ferreira Silva \\ Universidade Federal de Viçosa - UFV \\ fabiana.silva@ufv.br

\section{3- Valderí de Castro Alcântara \\ Universidade Federal de Viçosa - UFV \\ valderi.alcantara@ufv.br} \\ 5- Luís César Dias Drumond \\ Universidade Federal de Viçosa - UFV \\ irriga@ufv.br
}

\author{
2- Edson Arlindo Silva \\ Universidade Federal de Viçosa - UFV \\ edsonsilva@ufv.br
}

\section{4- Raiane Ribeiro Machado \\ Universidade Federal de Viçosa - UFV \\ raianemachado@ufv.br}

\author{
6- André Cezar de Souza \\ Universidade Federal de Viçosa - UFV \\ andre.cezar@ufv.br
}

Diego Maganhotto Coraiola - Editor

\section{RESUMO}

O estudo objetivou mostrar dentro do contexto atual as potencialidades e limitações que circundam as parcerias existentes entre as organizações públicas e privadas localizadas na região do Alto Paranaíba, Minas Gerais. Foram incorporados à discussão elementos que possam caracterizar ações e iniciativas, entre o público e o privado, voltadas ao desenvolvimento sustentável da região pesquisada. Para isso, informações oriundas do Zoneamento Ecológico-Econômico do Estado de Minas Gerais (ZEE-MG) contribuíram significativamente para análise dos dados e informações coletadas. Nesse contexto, foi possível identificar grande potencial para desenvolvimento do agronegócio, além da riqueza em recursos hídricos e da biodiversidade existente. Tais fatores propiciam o crescimento econômico da região, servindo de parâmetro para se pensar ao mesmo tempo em desenvolvimento sustentável. Sendo assim, vários foram os componentes institucionais pesquisados nos 31 municípios pertencentes ao Alto Paranaíba, podendo ser vistos como potenciais geradores de políticas públicas e parcerias voltadas para a sustentabilidade da região. Os resultados encontrados apontaram para cenários de potencialidades e limitações, desafios e expectativas, mas alertando para o contínuo e ininterrupto monitoramento do meio ambiente da região. As Considerações do estudo nos permitem em primeiro plano destacar a função social das organizações estudadas, principalmente em relações coletivas ou por meio de redes institucionais e segundo, algumas evidências encontradas até então, permitiram a incorporação de novas questões e objetivos específicos ao estudo, contribuindo atualmente para futuras questões ambientais.

Palavras-Chave

Desenvolvimento sustentável. Instituições públicas e privadas. Alto Paranaíba.

\section{ABSTRACT}

This study aimed to show in the current context the potentials and limitations surrounding the existing partnerships between the public and private organizations located in the Alto Paranaíba, Minas Gerais. At the discussion were incorporated elements that can characterize actions and initiatives between the public and private, aimed at developing the area searched. For this, information resultant of the Zoneamento Ecológico-Econômico of the State of Minas Gerais (ZEE-MG) contributed significantly to data analysis and information collected. In this context, it was possible to identify great potential for development of agribusiness, in addition to the wealth of water region, serving as a parameter to consider while sustainable development. Therefore, several institutional components were investigated in 31 municipalities belonging to the Alto Paranaíba and can be viewed as potential generators of public policies and partnerships towards the sustainability of the region. The results pointed to scenarios of potential and limitations, challenges and expectations, but attention to the continuous and uninterrupted monitoring of the environment of the region. The considerations of the study allow us to highlight in the foreground the social function of the organizations studied, especially in relations by means of collective or institutional networks and second, some evidence found so far, allowed the incorporation of new issues and goals specific to the study, and contributing now to further environmental issues.

Keywords

Sustainable Development. Public and private institutions. Alto Paranaíba. 


\section{Introdução}

A pesquisa apresentada aborda as potencialidades e limitações que circundam as parcerias existentes entre as instituições públicas e privadas, voltadas para a geração de desenvolvimento sustentável. Para tanto os arranjos institucionais presentes na região do Alto Paranaíba, Minas Gerais, constitui-se como objeto de estudo da pesquisa. Para a concretização do objetivo proposto contou-se com informações advindas do Zoneamento Ecológico-Econômico do Estado de Minas Gerais (ZEE-MG) que foi publicado em 2008. A classificação no que concerne a "Potencialidade Social" proposta pelo ZEE-MG foi o principal referencial na busca por dados dos 31 municípios da Região do Alto Paranaíba.

A referida pesquisa trabalhou com a perspectiva de que as instituições são fundamentais para a geração de desenvolvimento sustentável e que "a presença e o funcionamento adequado das instituições em um município, tornam-se uma condição decisiva para o desenvolvimento local sustentável", já que elas são "responsáveis pelo bom funcionamento da sociedade associado ao crescimento, desenvolvimento e eqüidade social" (ZEE-MG, 2008, p.101).

Semelhantemente à análise do ZEE, este trabalho se constituiu de uma abordagem quantitativa e através da qual foi feito 0 mapeamento das instituições delineadas pelo ZEEMG e que estão presentes nos 31 municípios da região. $A$ abordagem quantitativa considera que a existência de "instituições é uma condição sine qua non para o desenvolvimento sustentável, pois a presença representa potencialidade" (ZEE-MG, 2008, p.101).

Assim, as instituições podem ser vistas como potenciais geradoras de políticas públicas e parcerias voltadas para a sustentabilidade da região. De acordo com o ZEE-MG (2008) ressalvase que esta situação não significa que essas instituições possuem efetividade em suas ações com a proposta de sustentabilidade. Uma posterior análise qualitativa (fase II do projeto desenvolvido) irá colocar em questão a percepção da população destes municípios acerca do desempenho dessas instituições.

Vale ressaltar que instituições "são entendidas aqui como organizações formais, de caráter público ou privado, voltadas para o atendimento público nos setores da saúde, da educação, do meio ambiente, da cultura, do lazer, da segurança, da economia, entre outros" (ZEE-MG, 2008, p.101).
Dentro deste escopo, neste trabalho, instituições e organizações serão consideradas como sinônimos.

Para a compreensão da função e importância destas instituições recorreu-se aos preceitos teóricos do institucionalismo que permitem entender as modernas organizações em um contexto de desafios sociais, culturais, políticos e econômicos, contribuindo ainda para a análise das mesmas enquanto promotoras de ações que veem nos problemas ambientais atuais a possibilidade da inserção de aspectos referentes ao desenvolvimento sustentável.

Ao debater o desenvolvimento sustentável fezse o levantamento do histórico da Revolução Verde, do Relatório Brundtland e do ZEE-MG (2008). Alguns teóricos dessa vertente também serão abordados, entre eles, Sachs (2004), Ferreira e Ferreira (1995), Cavalcanti (1995) e Ehlers (1999), os quais, salvaguardadas as visões de cada autor sob a temática "desenvolvimento sustentável", haveria a necessidade de um novo estilo de desenvolvimento, assentado na equidade social, no qual deveria haver uma harmonização entre os objetivos socioeconômicos e ambientais.

\subsection{Desenvolvimento sustentável do local ao global}

A partir das primeiras décadas do século $X X$ as sociedades modernas começam a sentir os efeitos negativos advindos das modificações climáticas em conseqüência da industrialização, fenômeno este, que ocorria praticamente em todos os continentes, de modo mais intenso na Europa e na América do Norte. Problemas como o aquecimento global, o desmatamento, o crescimento populacional desordenado, o aumento da área destinada a agropecuária e a exploração desorganizada dos recursos naturais vêm comprometendo de maneira preocupante 0 equilíbrio entre crescimento econômico e a preservação do meio ambiente.

Em 1948, estudiosos da área ambiental e demais interessados no tema se reuniram para discutir a problemática "meio ambiente". Essa reunião culminou, posteriormente, na formação do "Clube de Roma" no qual se constatou, em primeira instância, a acentuada deterioração e degradação da natureza.

Seguindo a mesma ótica em termos de preocupação ecológica proposta pelo "Clube de Roma", tendo em vista a problematização e a busca de soluções para as questões ambientais, Cavalcanti (1995) destaca que, em 1972, a Organização das Nações Unidas (ONU), organizou na cidade de Estolcomo, Suécia, uma conferência 
de proporções globais. Esta conferência objetivava promover debates em torno da deterioração do meio ambiente em detrimento do avanço, cada vez mais acentuado, do processo de industrialização e do crescimento populacional vertiginoso. A conferência terminou com a confecção de um documento conhecido pelo nome de "Declaração sobre o Ambiente Humano" que contribuiu, mais tarde, para sensibilizar autoridades de diversos países do mundo e introduzir o tema na agenda política internacional.

Assim, a conferência de Estolcomo de 1972 funcionou como instrumento de sensibilização e conscientização ambiental. As idéias difundidas contribuíram, posteriormente, para a organização de eventos internacionais para tratar das questões ambientais como a ECO-92, a Rio +10 e o encontro de Kyoto (MDA/CONDRAF ${ }^{1}$, 2006).

É neste contexto de ameaças e oportunidades, no que se refere à relação homem-meio ambiente, que o trabalho em evidência se desenvolveu mostrando as potencialidades e limitações em torno das parcerias existentes entre organizações públicas e organizações privadas presentes na região do Alto Paranaíba, Estado de Minas Gerais voltadas para o desenvolvimento sustentável.

Nessa perspectiva, o Estado passa a exercer um papel de criador, orientador, executor, fomentador e legitimador no processo de consolidação de políticas públicas e de parcerias público-privadas.

\begin{abstract}
Quando se pensa nas possibilidades de um novo estilo de desenvolvimento, isso implica reconhecer que o Estado desempenha papel indispensável como indutor e gerenciador de uma parte dessas transformações. No entanto, a gestão pontual e corretiva não é satisfatória porque a questão ambiental é indissociável da pauta de prioridades dos programas de desenvolvimento. Dessa forma esse tipo de gestão teria que ser compartilhado entre Estado, a sociedade civil, o setor privado e as comunidades locais (FERREIRA e FERREIRA, 1995, p. 29).
\end{abstract}

Assim, é possível cogitar em organizações públicas e privadas que possam pensar, no contexto atual, nas transformações que vêm ocorrendo em relação ao meio ambiente. É preciso que o conjunto de ações governamentais e privadas direcionadas à questão ambiental possam receber o apoio e o devido significado da população, já que a parceria entre Estado e sociedade tende a corroborar para que as mazelas sócio-ambientais possam entrar na pauta dos governantes e de empresas privadas, convertendose em políticas e ações efetivas de sustentabilidade.

\section{Região do Alto Paranaíba: Características e Potencialidades}

A região do Alto Paranaíba totaliza uma área de $36.826 \mathrm{~km}^{2}$ (6,3\% do território mineiro) e possui população estimada em aproximadamente 643 mil habitantes. Neste caso, municípios como Araxá, Carmo do Paranaíba, Coromandel, Ibiá, Monte Carmelo, Patos de Minas, Patrocínio, Perdizes, Rio Paranaíba, Sacramento, São Gotardo e Tiros são considerados os principais da região por apresentarem contribuições significativas nas áreas da agricultura, pecuária e mineração, formando um importante complexo agropecuário e de mineração que movimenta a economia regional (IBGE, 2008).

De acordo com dados do IBGE (2008) a região do Alto Paranaíba possui várias características e potencialidades que a coloca de um lado, como principal celeiro de produção do Estado de Minas Gerais, e de outro, como possuidora de um potencial ecossistema, sendo a região rica em termos de biodiversidade regional caracterizada pelo cerrado. Na região se encontra a nascente do Rio Paranaíba que, juntamente com o Rio Grande, contribuem para a formação do Rio Paraná. Outro fator que coloca a região em destaque na dimensão ecológico-econômica é o fato de a mesma manter proximidade com a Serra da Canastra onde nasce um dos rios mais importante do país, qual seja, o Rio São Francisco, permitindo ao mesmo tempo a exploração de atividades turísticas, contribuindo para gerar trabalho e renda à população local (IBGE, 2008).

As características e potencialidades da região do Alto Paranaíba sobre "desenvolvimento sustentável" possuem no Zoneamento do Estado de Minas Gerais uma de suas principais fontes para melhor elucidá-las.

O relatório intitulado Zoneamento EcológicoEconômico do Estado de Minas Gerais (ZEE-MG) reflete a parceria conjunta entre as seguintes organizações e órgãos: de um lado a Secretaria de Meio Ambiente e Desenvolvimento Sustentável do Estado de Minas Gerais (SEMAD) e do Instituto Estadual de Florestas (IEF) e, do outro, contou com a participação da Universidade Federal de Lavras (UFLA), do Instituto Mineiro de Gestão das Águas (IGAM), da Fundação João Pinheiro (FJP) e da empresa Del Rey Engenharia. Essas organizações somaram esforços para construir um potencial instrumento de diagnóstico que vem servindo ao governo mineiro para planejamento de suas ações, tomada de decisões e elaboração de políticas públicas focalizadas. Contribuirá ainda para a celebração de parcerias entre o governo e a iniciativa privada. 
Neste caso, o propósito fundamental do ZEEMG encontra-se intimamente ligado com as possibilidades de contribuição para a definição de áreas ou zonas estratégicas, para se pensar o desenvolvimento sustentável no Estado de Minas Gerais, servindo de suporte para a orientação dos investimentos do governo e da sociedade em geral.

O Zoneamento Ecológico-Econômico tem como intuito compreender o processo de intervenções tanto por parte do Estado quanto por parte dos atores sociais atuantes na sociedade, o que inclui os investimentos e parcerias com as organizações privadas.

Dessa forma, o conceito de "desenvolvimento sustentável" é entendido a partir das discussões sobre a transformação e modernização da agricultura, advindas da chamada "Revolução Verde". Assim, segundo Ehlers (1999), a evolução da dinâmica de modernização dada pela Revolução Verde revelou graves impactos sobre o meio ambiente, que ocorriam de forma lenta e se situavam em dimensões locais. Posteriormente, a preocupação com a natureza atingiu esferas globais.

Diante de situações alarmantes em termos ambientais e da necessidade de novo rumo desenvolvimentista, o ZEE-MG (2008) introduz nas discussões voltadas para as questões ambientais e econômicas o conceito de "Potencialidade Social" e "Vulnerabilidade Natural".

A "potencialidade social" ${ }^{2}$ é entendida como um "conjunto de condições atuais, medido pelas dimensões produtiva, natural, humana e institucional, que determina o ponto de partida de um município ou de uma micro-região para alavancar o desenvolvimento sustentável" (ZEEMG, 2008, p.04). Percebe-se que essas dimensões ligadas à "potencialidade social" são amplas e requer um direcionamento para áreas que apresentam características específicas, como é o caso da região do Alto Paranaíba. Em relação ao conceito de "vulnerabilidade natural" suas diretrizes visam chamar a atenção para a "incapacidade do meio ambiente de resistir ou recuperar-se de impactos negativos antrópicos. Pressupõe-se uma situação atual que deve persistir ou se recuperar" (ZEE-MG, 2008, p. 04).

Os resultados do ZEE-MG revelaram que, em geral, os municípios pertencentes ao Alto Paranaíba apresentam condições muito favoráveis no que tange às respostas de investimentos a serem alocados, podendo ser amplamente convertidos em ações e políticas de sustentabilidade para a região. São municípios, de forma conjunta, com alta capacidade em impulsionar investimentos e políticas públicas voltadas para o desenvolvimento sustentável, tendo como critério básico desta constatação as diretrizes norteadoras da "potencialidade social" e dos aspectos ligados à "Vulnerabilidade Natural".

Posteriormente, será apresentada a classificação no que concerne a "potencialidade social" no âmbito dos 31 municípios que compõe a região do Alto Paranaíba.

\subsection{O papel do Estado no Alto Paranaíba: trajetórias históricas}

As constantes intervenções do Estado brasileiro na região do cerrado, o que inclui principalmente a região do Alto Paranaíba, culminaram com o advento de planos, programas e políticas governamentais que viam neste espaço territorial uma maneira de dinamizar em grande escala de produção, "novas" áreas para a expansão da agricultura e da pecuária. Dentre as principais ações governamentais implementadas na região do cerrado, com intuito de acelerar a ocupação desta região por atividades ligadas à agropecuária, podem ser destacadas as seguintes: constituição do Programa de Assentamento Dirigido do Alto Paranaíba (PADAP), incentivado pelo governo do Estado de Minas Gerais; implementação do Programa de Desenvolvimento dos Cerrados (POLOCENTRO) e do Programa de Cooperação Nipo-Brasileira para o Desenvolvimento dos Cerrados (PRODECER), estes dois últimos elaborados e coordenados pelo governo federal.

Em relação ao PRODECER, ressaltam Vasconcelos e Santos (2003) que, em 1961, no governo de Goulart, iniciam-se os primeiros contatos, entre o governo brasileiro em parceria com o governo japonês, para lançar as bases necessárias para a criação do Programa de Cooperação Nipo-Brasileira para o Desenvolvimento dos Cerrados (PRODECER); este, a partir da parceria Brasil-Japão, simbolizou um conjunto de ações canalizadas no meio rural tendo em vista a modificação do cerrado e a difusão de cultivos agrícolas que pudessem contribuir para dinamizar a agricultura e a pecuária brasileira.

No que se refere ao POLOCENTRO, este simbolizou um conjunto de iniciativas por parte do governo federal em gerar as condições cabíveis para proporcionar a ocupação racional e ordenada das áreas de cerrado (LIMA E RIBEIRO, 2003).

$\mathrm{Na}$ tentativa de incorporar aproximadamente 3,7 milhões de hectares de cerrados, foram utilizados 
diversos recursos políticos e financeiros no POLOCENTRO, sendo destinados: 1,8 milhões a pecuária e 700 mil ao florestamento-reflorestamento. A área de atuação do POLOCENTRO abrangia os estados de Mato Grosso, Mato Grosso do Sul, Goiás e as regiões do Triângulo Mineiro, Alto Paranaíba, Alto e Médio São Francisco e Vão do Paracatu, todas no Estado de Minas Gerais. (SILVA, 2000, p. 31).

Neste contexto, a modernização da agricultura idealizada no cenário brasileiro era direcionada para a aquisição de técnicas agrícolas advindas do Movimento de Expansão da Agricultura Mundial, historicamente conhecido como Revolução Verde.

\begin{abstract}
Atualmente o cerrado brasileiro se configura como uma paisagem que se renova de forma constante segundo ritmos e interesses do capital. Essa paisagem representada pelos cultivos quilométricos altamente mecanizados, com tecnologia de última geração, tanto no que diz respeito ao uso de insumos químicos, quanto de maquinários e equipamentos agrícolas, revela também, de um lado o perfil de agricultores bem sucedidos, sendo que de outro lado, nem sempre revela o custo social provocado pela implantação de um modelo de desenvolvimento que custou a exclusão de milhares de pequenos agricultores, posseiros e arrendatários (LIMA; RIBEIRO, 2003, p. 2).
\end{abstract}

De modo geral, o ideal capitalista de produtividade agrícola e as premissas praticadas no âmbito da Revolução Verde consistiam na disseminação de tecnologias voltadas para a utilização de agrotóxicos, defensivos e fertilizantes; na periodicidade de adubação do solo; na mecanização das atividades de produção agrícola; e na exploração desorganizada dos recursos naturais.

Já em relação ao Programa de Assentamento Dirigido do Alto Paranaíba (PADAP), considerado um programa focalizado exclusivamente na região objeto de estudo da pesquisa em evidência, este se desenvolveu sob a ótica de diretrizes voltadas ao desenvolvimento e mecanização da agricultura no cerrado. Para Silva (2000), o PADAP foi implementado em 1973 e funcionou como instrumento de exploração agrícola intensiva. Este programa atuou em uma área de aproximadamente 60.000 hectares, incorporando em suas ações municípios da região do Alto Paranaíba, constituindo-se em quatro núcleos de colonização na região.

De modo geral, os programas governamentais como o PADAP, PRODECER e POLOCENTRO, para além de seus pontos positivos e negativos, trouxeram em suas ações um cenário de impactos ambientais adversos em conseqüência da acentuada e "predatória" modernização da agropecuária no cerrado brasileiro. Tais impactos ambientais se fazem ainda presentes pela contaminação química advinda do uso excessivo de fertilizantes e defensivos agrícolas no solo e nas águas de rios e córregos que cortam o cerrado, e que de certa forma servem como fontes de irrigação de lavouras e abastecimento de água para os municípios da região. Com o passar do tempo essas ações começaram a refletir no melhoramento das atividades ligadas a agricultura e a pecuária, mas em contrapartida geraram algumas adversidades como a deterioração do solo, desmatamento das áreas nativas e contaminação de rios e nascentes junto ao ecossistema presente na região.

\subsection{A região do Alto Paranaíba na visão do ZEE- MG}

O "Zoneamento Ecológico-Econômico do Estado de Minas Gerais" revela que os municípios que formam as regiões do Triângulo Mineiro e Alto São Francisco, que inclui a região do Alto Paranaíba, estão em condições "muito favoráveis" para gerar desenvolvimento sustentável, tendo como critério de análise um conjunto de categorias classificatórias em termos de potencialidades produtiva, natural, humana e institucional, cujos resultados variam entre "Muito Favoráveis" a "Muito Precários". Os municípios que apresentam condições gerais semelhantes, como ponto de partida "muito favoráveis", são vistos com melhores condições de gerar desenvolvimento sustentável, em comparação com todos os demais municípios do Estado de Minas Gerais.

\begin{abstract}
Esta situação se traduz na capacidade que possuem de oferecer resposta superior aos investimentos realizados em áreas estratégicas ou em setores específicos. Neste caso, são municípios que possuem capacidades nos níveis estratégico, tático e operacional de serem facilmente estimulados para alavancar o desenvolvimento sustentável local e da micro-região (ZEE-MG, 2008, p. 67).
\end{abstract}

A classificação referente a "potencialidade social" para a região do Alto Paranaíba se apresenta da seguinte forma: 16 dos 31 municípios são classificados como "muito favoráveis" e estes apresentam,

\begin{abstract}
condições gerais semelhantes, como ponto de partida favorável para o desenvolvimento sustentável, em comparação com todos os municípios do Estado de Minas Gerais. Esta situação se traduz na capacidade que possuem de oferecer resposta proporcional aos investimentos realizados em áreas estratégicas ou setores específicos, concentrando-se em níveis estratégicos e táticos tendo em vista o estímulo por parte de políticas públicas e por investimentos setoriais voltados para o desenvolvimento local (ZEE-MG, 2008, p. 68).
\end{abstract}

Os municípios classificados como "Favoráveis" totalizam 13 dos 31 municípios da Região do Alto Paranaíba. 
Finalmente, os municípios classificados como "pouco favorável" foram identificados como aqueles que expressam, "condições gerais semelhantes, como ponto de partida pouco favorável para o desenvolvimento sustentável" (ZEE-MG, 2008, p. $68)$.

Os municípios classificados como "pouco favorável" são apenas 2 dos 31 municípios da Região do Alto Paranaíba (Santa Rosa da Serra e Guimarânia). Portanto, pode-se afirmar que a região, de modo geral, apresenta em quase sua totalidade municípios aptos e com um conjunto de condições (social, humana, natural, política, institucional, econômica e produtiva) significativas para implementar ações e políticas voltadas ao desenvolvimento sustentável. Nota-se que em uma escala classificatória que vai de "muito favorável" a "muito precário" (muito favorável; favorável; pouco favorável; precário; muito precário), nenhum dos 31 municípios do Alto Paranaíba, apresentaram situação "precária" ou "muito precária" no que se refere ao potencial particular de cada município para gerar desenvolvimento sustentável (ZEE-MG, 2008).

Os resultados desta pesquisa para o Alto Paranaíba sugerem que a rede de organizações (públicas e privadas) da região possui alto potencial para desenvolver políticas públicas e ações privadas ou conjuntas (Parceria Público-Privado) direcionadas à sustentabilidade.

Contudo, no âmbito dos Estudos Organizacionais a Teoria do Institucionalismo oferece elementos que permitem melhor compreensão das instituições modernas no contexto atual.

\section{Teoria do Institucionalismo}

A teoria do institucionalismo permite a compreensão das modernas instituições em um contexto de alta competitividade mediante a existência de desafios sociais, culturais, políticos e econômicos, contribuindo ainda para a análise das instituições enquanto promotoras de ações que vê nos problemas ambientais atuais a possibilidade da inserção de aspectos referentes ao desenvolvimento sustentável. Dessa confrontação de idéias e perspectivas teóricas surgem novas formas de organização dentro das instituições. Sendo assim, foi Philip Selznick que primeiro se preocupou em trazer à tona a necessidade de discutir a emergência de um modelo institucional capaz de proporcionar a substituição dos fatores técnicos por fatores ligados aos valores que, consequentemente, seriam determinantes no desenvolvimento das tarefas organizacionais (TOLBERT e ZUCKER, 2006; BOWRING, 2000).

Para Peci (2005), os debates teóricos feitos pelas correntes da Teoria Institucional introduzem nas discussões o "conceito de ambiente" como forma de influência e mudança dos aspectos intrínsecos e extrínsecos à organização, pois a ênfase no ambiente tornou-se a principal contribuição da Teoria Institucional. Para dar conta do entendimento a respeito da "questão do ambiente" os teóricos da organização se remetem a duas abordagens teóricas importantíssimas, quais sejam, a Teoria de Sistemas e a Teoria Contigencial (Tolbert e Zucker, 2006). Contudo, vale ressaltar, que a inserção do ambiente no estudo da Teoria Organizacional promoveu um importante avanço no processo de compreensão e interpretação dos aspectos administrativos e de gestão como identificado por Machado-da-Silva e Gonçalves (2000).

O ambiente concebido como algo incerto, mutável ou não gerenciável sugere que as decisões e análises sejam direcionadas não só para as condições e fatores internos, mas, principalmente, para fatores externos à organização que incluem desde outras organizações, consumidores e inovações tecnológicas até a questão ecológica e os valores culturais da comunidade na qual a organização encontra-se inserida, seja ela, uma cidade, grupo de indivíduos, estado ou nação.

Tal preocupação teve início a partir da visão sistêmica da administração, que buscou compreender as organizações como um sistema aberto que importa e exporta informações e recursos (financeiros, materiais, humanos, ideológicos, dentre outros) do ambiente, sendo uma fonte inesgotável de inputs para a sua estruturação, desenvolvimento, mudança e adaptação. De acordo com Bowring (2000), à luz desses aspectos ambientais, a organização pode ser entendida como um subsistema de um sistema maior de organizações, e será um sistema quando for comparada às suas partes ou subsistemas que a constitui (formas de gestão, tipos de liderança, marketing, finanças, materiais, fator humano $\mathrm{e}$ outros).

Posteriormente, a Teoria Contingencial, ao tratar do aspecto ambiental das organizações, preconiza a não existência de uma estrutura organizacional pronta e acabada ou única e infalível que possa ser eficiente e eficaz para todas as organizações, servindo de modelo para as demais. É importante destacar que as estruturas organizacionais são definidas por fatores, intitulados de contingenciais, que podem ser: dimensão da organização, formas 
de incorporação de tecnologias, tipologias de estratégia adotada e incerteza das tarefas. Esses fatores são produtos do ambiente em que as organizações se encontram inseridas, existindo uma adequação da sua estrutura aos seus fatores contingentes, e concomitantemente ao ambiente (TOLBERT e ZUCKER, 2006).

Essas considerações podem levar à constatação de que os fatores externos à organização como as questões ecológicas, culturais, econômicas, tecnológicas, sociais, políticas, ideológicas e legais interferem, diretamente ou indiretamente, no ambiente da organização, influenciando-a ao mesmo tempo em que as organizações influenciam o ambiente, pois existe necessariamente uma relação de reciprocidade e interdependência da organização com o ambiente externo. Por conseguinte, a Teoria Contingencial pode ajudar a explicar como a organização se relaciona com o ambiente, determinando uma relação entre as condições do ambiente e os processos de gestão mais adequados para atingir suas atribuições. Mas, salienta-se que esta abordagem pode melhor ser reconhecida pelos seus aspectos pró-ativos, por estar adequando situações ambientais e condutas de gestão de maneira integrada.

As organizações, com o tempo, são transformadas em instituições, por serem sistemas sociais que possuem metas e procedimentos estabelecidos, tendo valores por trás de requerimentos técnicos, reiterando, neste trabalho as instituições e organizações são tratadas como sinônimos dentro da perspectiva do ZEE-MG (2008).

As discussões sobre 0 institucionalismo (transitando entre o "velho" e o "novo"), de maneira conjunta, referem-se aos esquemas interpretativos e cognitivos dos tomadores de decisões institucionais para verificar as mudanças que podem vislumbrar alternativas metodológicas para a área institucional. Dessa confrontação de idéias e perspectivas teóricas surgem novas formas de organização dentro das instituições. Portanto, o institucionalismo passou a investigar "modelos teóricos institucionais" capazes de promover a substituição de elementos técnicos por elementos ligados aos valores (principalmente os relacionados aos aspectos culturais) que, conseqüentemente, seriam determinantes no desenvolvimento das atividades institucionais (BOWRING, 2000)

Neste ínterim, o institucionalismo se torna essencial para a compreensão da legitimação das ações voltadas para a construção de parcerias público-privadas e que possui potencial para a geração de desenvolvimento sustentável.

Neste caso, foram consideradas as organizações presentes na região do Alto Paranaíba, permitindo compreender os seguintes fatores: a capacidade institucional das organizações públicas e privadas para gerar desenvolvimento sustentável; ações que corroboram para a formação de redes institucionais como a criação de associações e consórcios interinstitucionais; identificou-se a existência de políticas públicas direcionadas às questões ligadas ao desenvolvimento sustentável; constatou-se ainda ações coletivas (parceria público-privada) em âmbito regional, canalizadas para a resolução da problemática sócio-ambiental, tendo como ponto de partida as necessidades, demandas, problemas e interesses que contribuem para configurar as organizações em redes institucionais. Todo este relato permitiu a análise das diretrizes que envolvem a capacidade institucional e gerencial dos municípios da região do Alto Paranaíba em promover políticas públicas e ações coletivas que almejam a sustentabilidade da região.

\section{Desenvolvimento Sustentável: Perspectivas e Limitações}

A noção de desenvolvimento sustentável origina-se a partir das discussões feitas pelo "Clube de Roma" em 1948 quando se identifica um aumento das atividades industriais em várias partes do mundo, aceleração do processo de degradação ambiental, aumento populacional significativo, poluição, crescimento desorganizado dos grandes centros urbanos e expansão da fronteira agrícola via desmatamento e inobservância dos limites de reservas legais (CAVALCANTI, 1995).

Com a constatação de distúrbios ambientais em quase todas as partes do mundo e com o crescimento acelerado das atividades industriais comprometendo consideravelmente a qualidade de vida, foi realizada em 1972, na cidade de Estolcomo, Suécia, uma conferência para tratar das questões ambientais objetivando promover debates em torno da problemática ambiental tendo por base expectativas em torno da transição de uma relação de deterioração dos recursos naturais para uma relação de desenvolvimento sustentável.

No entendimento de Ehlers (1999), a Conferência de Estolcomo, dentre várias temáticas discutidas, chamou a atenção do mundo para a sensibilização e conscientização da problemática ecológica e preservação do meio ambiente. Tratava-se da constituição de uma proposta ampla, 
permanente e duradoura para colocar na agenda mundial a questão sobre meio ambiente. Esta proposta visava criar as condições necessárias para minimizar os efeitos negativos advindos do processo de industrialização via crescimento econômico. Esta conferência é considerada um marco político-internacional para o surgimento de políticas de gerenciamento ambiental. Foram propostos novos conceitos como o de "Ecodesenvolvimento", simbolizando uma nova visão entre meio ambiente e crescimento econômico. Simultaneamente foram gerados e criados novos importantes programas, como o das Nações Unidas para o Meio Ambiente (PNUMA). Documentos de relevância foram protocolados, sendo a "Declaração sobre Meio Ambiente Humano e o Plano de Ação Mundial" o que mais se destacaram e obtiveram expressividade. A partir deste momento surgiu o conceito de ecodesenvolvimento, tendo Sachs (2004) seu criador e difusor. O eco-desenvolvimento surgiu do intuito de evidenciar o fato de que a poluição não reconhece limites políticos ou geográficos e afeta países, regiões e pessoas para muito além do ponto onde foi gerada. Sob esta ótica surge o conceito de "desenvolvimento sustentável".

\begin{abstract}
Pode-se conceituar desenvolvimento sustentável como um processo de transformação que ocorre de forma harmoniosa nas dimensões espacial, social, ambiental, cultural e econômica a partir do individual para o global. Essas dimensões são interrelacionadas por meio de instituições que estabelecem as regras de interações e que também influenciam no comportamento da sociedade local. A compreensão desse processo deve ocorrer de forma contínua e observando-se as adaptações do sistema, tendo como base a sociedade e suas interrelações e interdependências como um sistema adaptativo complexo (SILVA e MENDES, 2005, p. 37).
\end{abstract}

Neste caso, observa-se que o conceito de desenvolvimento sustentável surge atrelado a outras categorias abrangentes e complexas como cultura, economia, territorialidade, demografia, aspectos sociais e ambientais, tendo na relação sociedade-meio ambiente o ponto de partida para sua efetiva consolidação. Historicamente o conceito de desenvolvimento sustentável somente atingiu níveis globais de discussões e importância a partir da década de 70 do século passado com a institucionalização das diretrizes traçadas por meio da conferência de Estolcomo. Assim, esta conferência significou em dimensões globais, o início de inúmeras iniciativas em prol da defesa da bandeira do desenvolvimento sustentável, que ampliado passou a ser entendido sob a luz da seguinte reflexão:

O conceito de desenvolvimento sustentável ocupa uma posição central dentro do ambientalismo, particularmente depois da publicação do relatório da Comissão Mundial sobre o Meio Ambiente e Desenvolvimento, 'Nosso Futuro Comum', em 1987 (mais conhecido como 'Relatório Brundtland'). Nos últimos anos, o antigo debate dos anos 70, que de certa forma tinha pensado por separado as questões ambientais e de desenvolvimento, é substituído por outro mais convergente e otimista, preocupado centralmente na questão de como fazer para alcançar um desenvolvimento sustentável (VIOLA e LEIS, 1995, p. 77).

Para Silva (2000 apud ZEE-MMA, 2002) a idéia de desenvolvimento sustentável surge como alternativa para reequilibrar a dicotomia entre preservação do meio ambiente e crescimento econômico, já que o desenvolvimento sustentável "demanda um novo processo de exploração dos recursos naturais e apropriação do território orientado pela premissa fundamental da valorização humana, levando em conta a sustentabilidade ecológica, social e econômica. (ZEE-MMA, 2002, p. 18).

Assim, o que se percebeu a partir da conferência de Estolcomo foi um movimento de direcionamento de ações públicas e privadas em torno das mazelas ambientais. Este cenário preocupante chamou a atenção de políticos, organizações sociais e ambientais, empresários, movimentos sindicais, organizações religiosas, privadas, públicas, dentre outras, que começaram a se mobilizar para suprir as carências encontradas em um universo ecológico de extrema preocupação.

Ferreira e Ferreira (1995) salientam que foi na década de 80 que as questões ambientais começaram a entrar na agenda do Estado, de políticos e sindicalistas que se utilizavam da "bandeira verde" para sensibilizar grupos da sociedade civil brasileira. As autoras exemplificam como extremo da situação crítica e degradadora a condição em que se encontrava a cidade de Cubatão, Estado de São Paulo, devido ao excesso de acúmulo de poluição, doenças e intensificação da atividade industrial.

Dessa forma, observa-se um movimento de vários atores sociais da sociedade brasileira no sentido de consolidar um conjunto de ações no âmbito político, legal e social que inclua políticas públicas e ações conjuntas da sociedade civil voltadas ao ecologismo, expressão esta que abrange toda a biodiversidade existente, nas mais heterogêneas regiões do país. Outro ponto a ser considerado é que algumas regiões do Estado de Minas Gerais, de maneira específica cita-se a região do Alto Paranaíba, estão sendo vistas por órgãos governamentais (FEAM, IBAMA, IGAM, dentre outros) e organizações de pesquisa 
(Embrapa, Fundação João Pinheiro, Epamig, Emater e Universidades, a título de exemplos) como uma região em potencial para desenvolver matrizes energéticas de bases sustentáveis, tendo em vista dois objetivos essenciais: primeiro a utilização de recursos renováveis e pouco poluentes; segundo a conscientização de que esses recursos advindos da agricultura possam minimizar os impactos de poluição e degradação da biodiversidade no território mineiro.

Nesta perspectiva, as organizações não-
governamentais e os grupos comunitários dedicados
à proteção ambiental são parte de um movimento
mais amplo que inclui: setores do empresariado
cujos sistemas produtivos preenchem em medida
significativa o critério da sustentabilidade, grupos e
instituições científicas cujo espaço de pesquisa
coloca-se no rumo da sustentabilidade, setores da
estrutura estatal (particularmente das agências
ambientais) que consideram a proteção ambiental
uma dimensão fundamental da ação de governo,
agências intergovernamentais orientadas para a
sustentabilidade planetária.
FERREIRA, 1995, p. 28-29).

Nesta oportunidade, o desenvolvimento sustentável surge como alternativa plausível para que os gestores públicos possam se referenciar ao tomar suas decisões e formular políticas públicas específicas voltadas para a área ambiental, sem, no entanto, descartar as possíveis parcerias público-privadas para tal. Neste caso, o ZEE-MG (2008) surge como uma importante ferramenta de orientação das questões ambientais, já que a mesma constitui-se em um conjunto de dados tanto na área ecológica quanto na econômica possibilitando a visualização panorâmica das regiões que formam o Estado de Minas Gerais e servindo ao poder público estadual como uma rica fonte de consulta no que tange à tomada de decisões estratégicas e elaboração de políticas públicas referentes aos aspectos de sustentabilidade ambiental e social.

Assim a noção de desenvolvimento sustentável a partir de dimensões que tendem a contribuir para um melhor direcionamento das ações governamentais dos municípios da região do Alto Paranaíba. Essas dimensões constituintes das áreas da produção agropecuária, biodiversidade, sociais humanísticas e instituições públicas e privadas corroboraram para que os objetivos desta pesquisa pudessem ser mensurados dentro de aspectos qualitativos e quantitativos. Tendo em vista estas dimensões, pode-se inferir que o conceito de "potencialidade social" foi um importante instrumento analítico-conceitual orientador das etapas investigadas no processo de desenvolvimento deste trabalho, já que permitiu identificar e analisar a configuração existente das principais organizações públicas e privadas da região do Alto Paranaíba, conhecendo suas potencialidades e fragilidades, ações e parcerias, além de fornecer uma visão panorâmica do atual cenário que possa ou não evidenciar aspectos ligados a sustentabilidade da região. Apresentando íntima relação com a sustentabilidade, a noção de potencialidade social passa a ser compreendida como "o conjunto de condições atuais, medido pelas dimensões produtiva, natural, humana e institucional, que determina o ponto de partida de um município ou de uma microrregião para alcançar o desenvolvimento sustentável" (ZEE-MG, 2008, p. 04).

Dessa forma, o desenvolvimento sustentável em consonância com a noção de potencialidade social almeja oferecer uma gama de fatores econômicos e ecológicos que possam, dentro de uma dimensão relacional entre sociedade e meio ambiente, elucidar evidências que sirvam de base para compreender como as organizações públicas e privadas da região do Alto Paranaíba adquirem "capacidade institucional" para gerar desenvolvimento sustentável. Considera-se que capacidade institucional refere-se a uma situação em que "o índice de um município será tanto maior quanto maior for a capacidade financeira do município e quanto melhor for a capacidade gerencial do município" (ZEE-MG, 2008, p. 31). Esta definição amplia as análises em torno da relação instituições-natureza, mostrando-nos os eventuais impactos que poderão surgir desta relação.

Observa-se que, além de adquirir capacidade institucional, determinado município deverá criar as condições necessárias para que a sua capacidade gerencial-financeira seja tão eficiente quanto for a sua capacidade institucional. Ambas as capacidades envolvem a alocação de recursos públicos por meio de políticas públicas e de parcerias com a iniciativa privada, neste caso, voltadas à sustentabilidade do meio ambiente e da sociedade. Para que isto comece a ocorrer, tornase indispensável o estímulo de ações coletivas e políticas governamentais que possam promover a sensibilização e conscientização da população (local, regional ou global) em relação à real importância que se deve direcionar, no momento atual, às questões ambientais. Trata-se, para além da preservação e do cuidado que se deve ter com o meio ambiente, de uma questão de sobrevivência da espécie humana.

\section{Procedimento Metodológico e Técnicas de Pesquisa}


No presente trabalho, o universo de pesquisa se constitui das instituições públicas e privadas, situadas na região do Alto Paranaíba, Estado de Minas Gerais e que refletem ações coletivas e políticas públicas, que levam ao desenvolvimento sustentável da região.

No que concerne a metodologia de pesquisa, tendo em vista a importância da coleta de dados e levantamento de informações, em poder das instituições públicas e privadas estudadas, bem como a teoria que fundamenta a prática, especial atenção foi direcionada para as técnicas e métodos de pesquisa propostos por Gil (2007) e Marconi e Lakatos (2003). Portanto, são métodos e técnicas voltadas à pesquisa quantitativa, sem, no entanto desconsiderar a perspectiva qualitativa.

Como um procedimento essencial de pesquisa no ver de Marconi e Lakatos (2003) e Gil (2007) é a Pesquisa Bibliográfica que consistiu no levantamento de todo o acervo bibliográfico possível acerca do tema estudado, publicado em periódicos nacionais e internacionais, livros, dissertações, teses, revistas científicas especializadas, dentre outras fontes bibliográficas. Toda a bibliografia selecionada, pertinente ao tema da pesquisa, foi lida, fichada e sistematizada em forma de texto teórico. Para Laville e Dionne (1999), esses procedimentos permitem equacionar categorias analíticas como "capacidade institucional" e "desenvolvimento sustentável", sendo estruturadas e analisadas ao longo do processo de pesquisa. Para Alexander (1999), a importância de recorrer a teorias que embasaram este estudo é fundamental, devido ao fato de "a razão é que a existência de discordâncias empíricas e ideológicas permite aos cientistas sociais operacionalizar proposições de modos diferentes" (Alexander, 1999, p. 40) gerando as bases para o confronto dos resultados obtidos com as teorias que deram suporte à pesquisa.

Outro tipo essencial de pesquisa consoante a Gil (2007) e Marconi e Lakatos (2003) é a Pesquisa documental. Neste trabalho ela se constituiu do levantamento de dados quantitativos.

Foram levantados informações e dados secundários que caracterizaram, numericamente, as organizações da região do Alto Paranaíba, no sentido de identificar e analisar as principais ações coletivas e políticas públicas que tem levado à geração de desenvolvimento sustentável. Isto significou saber em quais circunstâncias as demandas sócio-econômicas e ecológicas da região foram identificadas; quais foram os critérios utilizados na seleção e implementação de políticas públicas e ações coletivas voltadas à sustentabilidade; que agentes sociais atuaram como parceiros e potenciais beneficiários deste tipo de iniciativa; constataram-se ainda a criação de núcleos, comitês, representações municipais, conselhos, comissões e associações para pensar a realidade com vistas à transformação local dos municípios em termos de sustentabilidade. Todos os documentos que foram gerados na identificação, elaboração, implementação e avaliação de ações coletivas e políticas públicas na região do Alto Paranaíba, constituíram fonte de informação documental.

\subsection{Sistematização e análise das informações coletadas}

Resumidamente, a análise das informações foi feita após cada etapa do trabalho de campo, consistindo na checagem de todo material coletado, sejam eles dados primários ou secundários, o que permitiu a orientação e realização da próxima etapa da pesquisa. Este procedimento foi imprescindível para compreender as ações envolvendo organizações públicas e privadas na geração de desenvolvimento sustentável. Segundo Alencar (2000), a seqüência de análises parciais facilita a interação da pesquisa qualitativa.

\begin{abstract}
A seqüência de análises parciais (trabalho de campo - análise - trabalho de campo - análise) indica o caráter interativo da pesquisa qualitativa, significando que as pressuposições do pesquisador, ao iniciar o estudo, podem ser modificadas durante o próprio processo de investigação, acarretando, por seu turno, a reformulação das questões de pesquisa ou, até mesmo, do problema de pesquisa. Seria, na linguagem de Denzin \& Lincoln, a reconstrução social da realidade (ALENCAR, 2000, p. 17)
\end{abstract}

Assim, parte dos dados brutos, como os dados secundários obtidos durante a coleta de informações foram primeiramente organizados para posteriormente, serem analisados. Ao serem apresentados neste artigo em quadros.

\section{Configuração Institucional do Alto Paranaíba}

Por meio do ZEE-MG foi possível configurar institucionalmente a região do Alto Paranaíba enquanto universo de investigação científica, tendo na capacidade institucional conjunta das organizações públicas e privadas, o ponto de partida para a compreensão de ações coletivas e políticas governamentais direcionadas para a prática de desenvolvimento sustentável.

\subsection{Componente institucional e as organizações do Alto Paranaíba}


Aqui, são apresentados os fatores condicionantes e os indicadores que fazem parte do componente institucional e o conjunto de organizações pertencentes aos municípios do Alto Paranaíba que formam o panorama institucional da região. Este panorama institucional, como será discutido em seguida, corrobora para vislumbrar possibilidades em se criar "redes de instituições" que possam atuar consideravelmente nas mazelas ambientais e sociais existentes nesta região, por meio de políticas e ações focalizadas. Sob a ótica das prerrogativas do desenvolvimento sustentável procurou-se enumerar os municípios que variam entre "muito favoráveis" a "muito precários" no que se refere à capacidade institucional individualizada de cada município. Tratou-se ainda em compreender o desempenho institucional dos municípios em gerar as condições necessárias por meio do uso diferenciado de formas de gestão pública.

Portanto, ao ser desmembrado, o ZEE-MG oferece um conjunto de categorias abrangentes como a relacionada ao "componente institucional". O componente institucional é composto por "fatores condicionantes" e "indicadores" que se encontram diretamente integrados entre si. Os "fatores condicionantes" se apresentam em número de seis e são eles: Capacidade Institucional, Organizações Jurídicas, Organizações Financeiras, Organizações de Fiscalização e Controle, Organizações de Ensino e Pesquisa e as Organizações de Segurança Pública.

Os "indicadores" totalizam-se em onze, sendo os mesmos apresentados abaixo, relacionando-se com seu(s) respectivo fator condicionante.

O Fator condicionante Capacidade Institucional possui quatro indicadores os quais são Gestão Municipal, Gestão do Desenvolvimento Rural, Gestão Ambiental Municipal e Gestão Cultural. Os fatores condicionantes, Organizações jurídicas, Organizações financeiras e Organizações de fiscalização e Controle, possuem apenas um indicador cada, sendo eles respectivamente, Presença de Organizações Jurídicas, Presença de Organizações Financeiras e Presença de Organizações de Fiscalização e Controle

O fator condicionante Organizações de Ensino e Pesquisa possuem dois indicadores, o primeiro é Organizações de Ensino Superior e Ensino Profissionalizante, e o segundo, Organizações de Pós-Graduação Stricto-Sensu e Pesquisa.

O fator condicionante organizações de segurança pública, também possuem dois indicadores: Unidades de defesa social e Capacidade de Aplicação da Lei. Ressalta-se que estes indicadores possuem por sua vez variáveis, índices e sub-índices (quadro abaixo).

\begin{tabular}{|c|c|c|}
\hline Componente & Fatores Condicionantes & Indicadores \\
\hline \multirow{11}{*}{ INSTITUCIONAL } & \multirow{4}{*}{ Capacidade Institucional } & Gestão Municipal \\
\hline & & Gestão do Desenvolvimento Rural \\
\hline & & Gestão Ambiental Municipal \\
\hline & & Gestão Cultural \\
\hline & Organizações Jurídicas & Presença de Organizações Jurídicas \\
\hline & Organizações Financeiras & Presença de Organizações Financeiras \\
\hline & Organizações de Fiscalização e Controle & $\begin{array}{l}\text { Presença de Organizações de Fiscalização e } \\
\text { Controle }\end{array}$ \\
\hline & \multirow{2}{*}{$\begin{array}{l}\text { Organizações de Ensino } \\
\text { E Pesquisa }\end{array}$} & $\begin{array}{l}\text { Organizações de Ensino Superior e Ensino } \\
\text { Profissionalizante }\end{array}$ \\
\hline & & $\begin{array}{l}\text { Organizações de Pós-Graduação Stricto-Sensu e } \\
\text { Pesquisa }\end{array}$ \\
\hline & \multirow{2}{*}{$\begin{array}{l}\text { Organizações de } \\
\text { Segurança Pública }\end{array}$} & Unidades de Defesa Social \\
\hline & & Capacidade de Aplicação da Lei \\
\hline
\end{tabular}

De acordo com informações do ZEE-MG (2008), o Componente Institucional encontra-se inserido dentro das dimensões da Potencialidade Social significando a capacidade institucional que os municípios possuem para identificar e atender as demandas sociais básicas dos indivíduos sejam elas relacionadas aos aspectos ecológicos, econômicos, políticos, culturais, dentre outros, onde houver a necessidade de intervenção do Estado de forma isolada, ou por meio de parcerias com a iniciativa privada.

Assim, ao ser acionado, o Componente Institucional procura avaliar não somente a presença de instituições - organizações - situadas nos 31 municípios que compõem a região do Alto Paranaíba (ver quadro abaixo), mas buscou, principalmente, compreender como estas instituições se articulam entre si para suprir as 
demandas da população local. Neste caso, a presença conjunta de instituições contribui para potencializar ações privadas e políticas governamentais que objetivem o desenvolvimento sustentável de um determinado município ou região.

De modo que, ao ser desmembrado, nota-se que o Componente Institucional do ZEE é constituído por seis fatores condicionantes e onze indicadores explicitando, através desses fatores condicionantes e indicadores, os reais objetivos que se pretendem ao se aplicar esta ferramenta ao panorama institucional do Alto Paranaíba. Assim, foi possível destacar a importância do fator condicionante "Capacidade institucional" dos municípios para este estudo, sem perder de vista as possíveis correlações entre este fator e os demais fatores condicionantes e indicadores que formam o componente institucional da região estudada.

Do ponto de vista administrativo, o componente institucional dos municípios da região do Alto Paranaíba reflete um conjunto de ações direcionadas para a estruturação da administração pública municipal, prezando por reformas e utilização de modelos de gestão voltados à participação popular e institucional, no momento em que as demandas locais forem identificadas. Almeja ainda, a confecção de uma administração pautada nos princípios da eficiência e da eficácia nos moldes do "choque de gestão" praticado pelo governo do Estado e de determinados processos gerenciais utilizados pela iniciativa privada. Assim, o componente institucional favoreceu a identificação da capacidade institucional de gestão de cada município da região, possibilitando avaliar se os modelos de administração pública praticados nos municípios do Alto Paranaíba contribuem para que os interesses públicos sejam amplamente discutidos e direcionados para a população local.

O quadro foi desenvolvido com base nos Indicadores e Fatores Condicionantes delineados nos estudos do ZEE-MG (2008), sendo que a maioria das variáveis do mesmo foi incorporada ao quadro, pois, são fundamentais para a geração de desenvolvimento sustentável. Apresentam-se estes delineados aos 31 municípios da Região do Alto Paranaíba de forma que possam melhor ser compreendidos. Ressalta-se que está pesquisa se constitui de dados quantitativos, assim como foi a realizada pelo Zoneamento. Após breve reflexão sobre este quadro, apresenta-se uma comparação entre três municípios, sendo eles Patos de Minas, Coromandel e Douradoquara.

Quadro 2 - Panorama das organizações presentes nos 31 municípios do Alto Paranaíba de acordo com o componente institucional do ZEE-MG (2008)

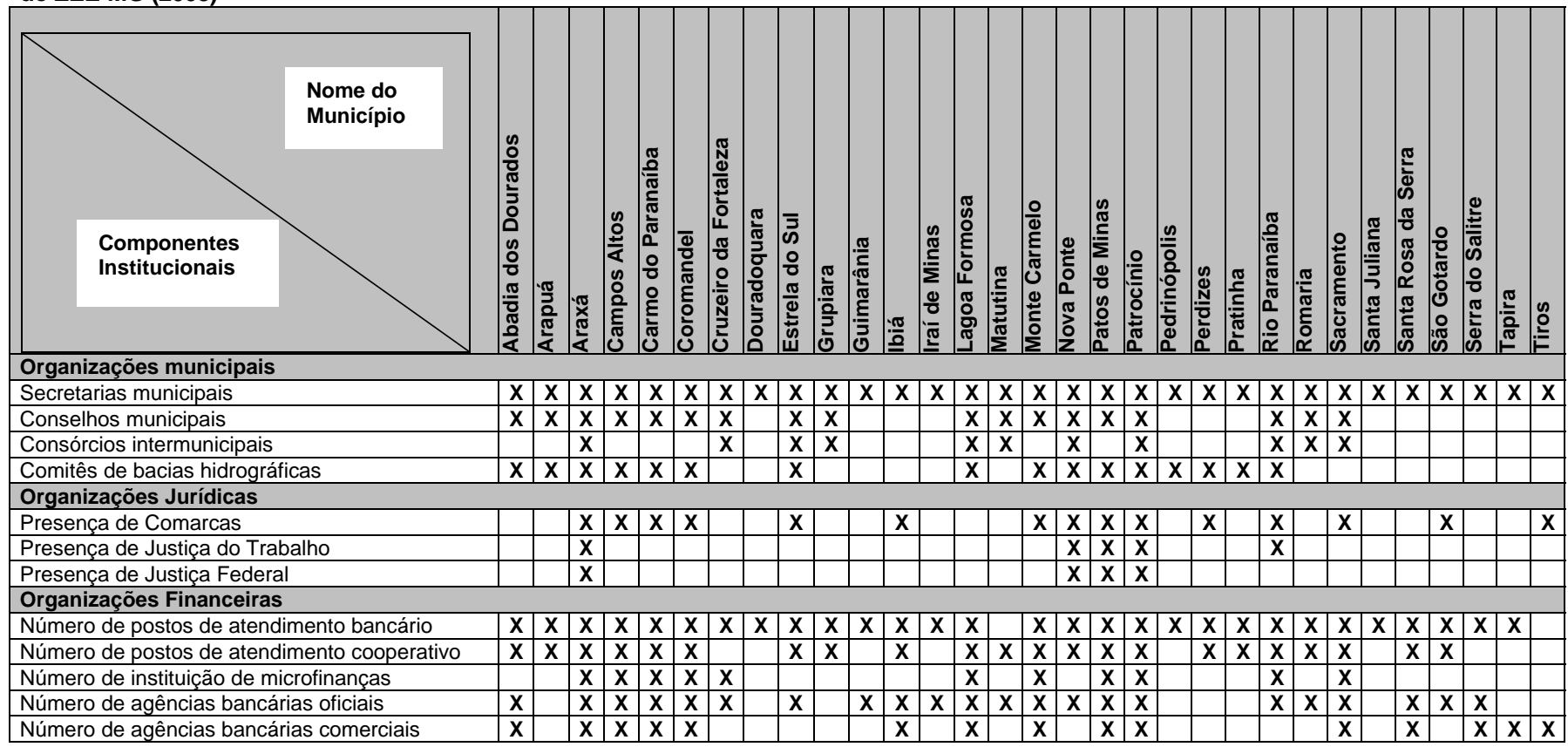


CONTINUAÇÃO... Quadro 2 - Panorama das organizações presentes nos 31 municípios do Alto Paranaíba de acordo com o componente institucional do ZEE-MG (2008)

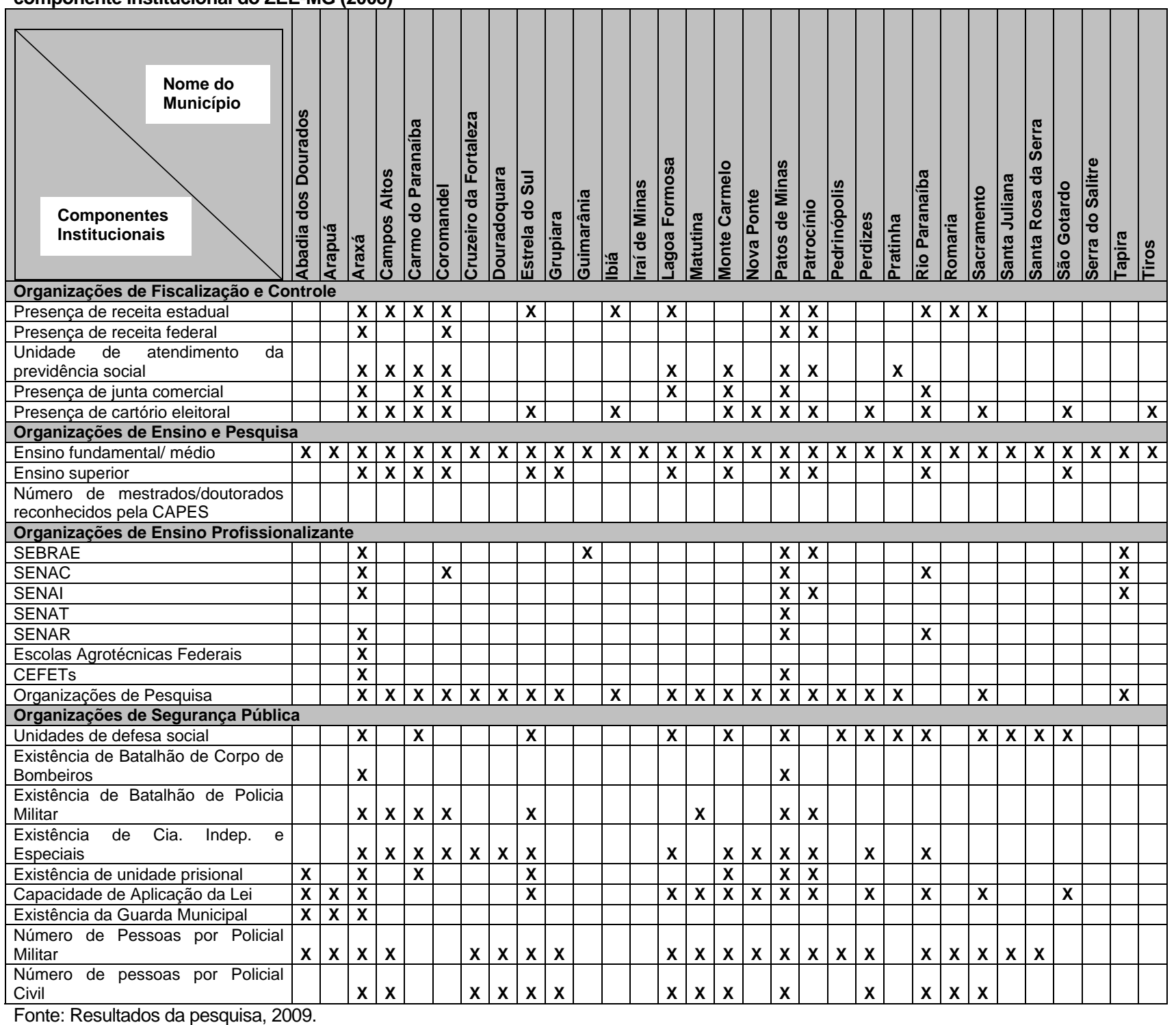

O quadro acima, construído por orientação do componente institucional, mostra ainda a distribuição referente às organizações presentes ou não nos 31 municípios que formam a região do Alto Paranaíba, possibilitando classificar estes municípios em "muito favoráveis", "pouco favoráveis" ou "muito precários", do ponto de vista da presença ou não do conjunto de organizações que integram o componente institucional da região.

As questões ambientais discutidas no mundo e no Brasil, com as quais nos defrontamos, não são novas, mas tais questões começaram a ser entendidas há pouco tempo atrás, devido a sua complexidade e vem ganhando importância de especialistas, governos e de instituições da sociedade civil organizada. Os questionamentos em relação aos problemas ambientais se intensificaram no decorrer do tempo, e em conseqüência, as exigências de estudos sobre esses problemas ganharam vigor e força, sendo que a sociedade passou a ser influenciada diretamente por meio de instituições situadas nas diferentes esferas do Estado Brasileiro (municipais, estaduais, distrital e federal), que passaram a possibilitar o acesso a essas informações.

Por meio do levantamento de dados secundários, foi possível identificar nos 31 municípios da região do Alto Paranaíba, as organizações neles presentes, de diferentes categorias e respondendo a interesses, demandas e necessidades diversas. Dentre os municípios alvo de estudo, três deles podem ser destacados: o primeiro por apresentar um grande número de organizações; o segundo por ser intermediário (agrupamento mediano de organizações) em termos de presenças institucionais e; por último, o 
terceiro município, apresentando poucas

de Minas, Coromandel e Douradoquara (ver quadro abaixo).

Nesse sentido, a partir de "fatores condicionantes" e "indicadores" contidos no componente institucional revelado pelo ZEE-MG (2008), constatou-se que o município de Patos de Minas possui potencial "muito favorável" para gerar desenvolvimento sustentável devido ao fato de ser o município mais bem estruturado em termos da presença de organizações, que respondem ou podem responder as várias necessidades e demandas da população e do meio ambiente. O município de Coromandel encontra-se em condições "pouco favorável"3 para gerar desenvolvimento sustentável. Já o município de Douradoquara apresentou situação "precária"4 no que se refere à geração de desenvolvimento organizações, sendo eles respectivamente, Patos sustentável, carecendo de uma rede institucional mais ampla e que responda às necessidades locais. Estes cenários expressam os esforços conjuntos das ações institucionais que vem ocorrendo no Alto Paranaíba.

Neste caso, várias foram as organizações pesquisadas nos três municípios em foco e nos demais, sendo eles organizações municipais, organizações jurídicas, organizações financeiras, organizações de fiscalização e controle, organizações de ensino e pesquisa, organizações de ensino profissionalizante e organizações de segurança pública, sendo perceptível a relação entre número de habitantes destes municípios e o número de organizações neles presentes, como retrata o quadro abaixo.

Quadro 3 - Análise comparativa do componente institucional entre municípios

Componente Instituciona

\begin{tabular}{|c|c|c|c|}
\hline Componente Institucional & Patos de Minas & Coromandel & Douradoquara \\
\hline \multicolumn{4}{|c|}{ Organizações Municipais } \\
\hline Secretarias municipais & $\mathbf{X}$ & $\mathbf{X}$ & $\mathbf{X}$ \\
\hline Conselhos municipais & $\mathbf{X}$ & $\mathbf{X}$ & \\
\hline \multicolumn{4}{|l|}{ Consórcios intermunicipais } \\
\hline Comitês de bacias hidrográficas & $\mathbf{X}$ & & \\
\hline \multicolumn{4}{|c|}{ Organizações Jurídicas } \\
\hline Presença de Comarcas & $\mathbf{X}$ & $\mathbf{X}$ & \\
\hline Presença de Justiça do Trabalho & $\mathbf{X}$ & & \\
\hline Presença de Justiça Federal & $\mathbf{X}$ & & \\
\hline \multicolumn{4}{|c|}{ Organizações Financeiras } \\
\hline Número de postos de atendimento bancário & $\mathbf{X}$ & $\mathbf{X}$ & $\mathbf{X}$ \\
\hline Número de postos de atendimento cooperativo & $\mathbf{X}$ & $\mathbf{X}$ & \\
\hline Número de instituição de microfinanças & $\mathbf{X}$ & $\mathbf{X}$ & \\
\hline Número de agências bancárias oficiais/ agências bancárias comerciais & $\mathbf{X}$ & $\mathbf{X}$ & \\
\hline \multicolumn{4}{|c|}{ Organizações de Fiscalização e Controle } \\
\hline Presença de receita estadual & $\mathbf{X}$ & $\mathbf{X}$ & \\
\hline Presença de receita federal & $\mathbf{X}$ & $\mathbf{X}$ & \\
\hline Unidade de atendimento da previdência social & $\mathbf{X}$ & $\mathbf{X}$ & \\
\hline Presença de junta comercial & $\mathbf{X}$ & $\mathbf{X}$ & \\
\hline Presença de cartório eleitoral & $\mathbf{X}$ & $\mathbf{X}$ & \\
\hline \multicolumn{4}{|c|}{ Organizações de Ensino e Pesquisa } \\
\hline Ensino fundamental/médio & $\mathbf{X}$ & $\mathbf{X}$ & $\mathbf{X}$ \\
\hline Ensino superior & $\mathbf{X}$ & $\mathbf{X}$ & \\
\hline \multicolumn{4}{|c|}{ Organizações de Segurança Pública } \\
\hline Unidades de defesa social & $\mathbf{X}$ & & \\
\hline Existência de Batalhão de Corpo de Bombeiros & $\mathbf{X}$ & & \\
\hline Existência de Batalhão de Polícia Militar & $\mathbf{X}$ & $\mathbf{X}$ & \\
\hline Existência de Cia. Independentes e Especiais & $\mathbf{X}$ & $\mathbf{X}$ & $\mathbf{X}$ \\
\hline Existência de unidade prisional/penitenciária & $\mathbf{X}$ & & \\
\hline Capacidade de Aplicação da Lei & $\mathbf{X}$ & & \\
\hline \multicolumn{4}{|l|}{ Existência da Guarda Municipal } \\
\hline Número de Pessoas por Policial Militar & $\mathbf{X}$ & & $\mathbf{X}$ \\
\hline Número de Pessoas por Policial Civil & $\mathbf{X}$ & & $\mathbf{X}$ \\
\hline \multicolumn{4}{|l|}{ Número de mestrado/doutorado reconhecidos pela CAPES } \\
\hline \multicolumn{4}{|c|}{ Organizações Ensino Profissionalizante } \\
\hline SEBRAE & $\mathrm{X}$ & & \\
\hline SENAC & $\mathrm{X}$ & $\mathrm{X}$ & \\
\hline SENAI & $\mathrm{X}$ & & \\
\hline SENAT & $\mathrm{X}$ & & \\
\hline SENAR & $\mathrm{X}$ & & \\
\hline \multicolumn{4}{|l|}{ Escolas Agrotécnicas Federais } \\
\hline CEFETs & $\mathrm{X}$ & & \\
\hline Organizações de Pesquisa & $\mathrm{X}$ & $\mathrm{X}$ & $\mathrm{X}$ \\
\hline
\end{tabular}

Fonte: Resultados da pesquisa, 2009 
A partir dos dados revelados pelo quadro acima, nota-se que o município de Patos de Minas se destacou entre os demais municípios pertencentes à região do Alto Paranaíba, por apresentar número maior de organizações que possibilitam ao mesmo desenvolver políticas e ações voltadas para diferentes setores da sociedade. Já o município de Coromandel se encontra em uma posição intermediária em relação aos demais e apresenta certa deficiência na categoria organizações de ensino profissionalizante, ao passo que o município de Douradoquara, classificado como sendo um dos municípios que possui o menor número de organizações entre os 31 existentes na região; mostra-se deficitário em todas as categorias institucionais do componente institucional, segundo dados referentes à pesquisa realizada.

No entanto, ressalta-se que a simples presença física de uma ou várias organizações em um determinado município não implica necessariamente que estas organizações em destaque corroboram para ações coletivas voltadas ao desenvolvimento sustentável. Por outro lado, a formação de uma rede institucional atuante e com ações bem definidas, tende a favorecer 0 desenvolvimento de políticas e ações que possam potencializar a sustentabilidade dos municípios do Alto Paranaíba.

Dentro do contexto atual os municípios do Alto Paranaíba devem ser vistos como potenciais geradores de políticas públicas e parcerias voltadas para a sustentabilidade da região, visto que as organizações identificadas e discutidas neste estudo em um momento ou outro podem expressar ações coletivas com vistas ao fortalecimento das questões ambientais existentes na região.

Nas subseções abaixo serão classificadas, em termos conceituais, a função e o papel exercido por cada organização que contribui para formar o componente institucional do Alto Paranaíba.

\subsubsection{Capacidade institucional municipal}

As organizações municipais são órgãos públicos que prestam serviços necessários à sociedade dentro de um território delimitado (município), atendendo a demandas e interesses coletivos. $\mathrm{Na}$ região do Alto Paranaíba, os seus 31 municípios possuem secretarias municipais que abrangem diversos setores, desde saúde e educação até meio ambiente, esporte e lazer. Grande parte desses municípios possui também conselhos municipais, tanto urbanos quanto rurais, que são responsáveis por emitir pareceres sobre determinados assuntos de interesses coletivos. Nos municípios pesquisados foram detectados consórcios de diferentes categorias e a existência de projetos em andamento para posterior implantação. Alguns municípios participam dos comitês de bacias hidrográficas, por ser a região privilegiada pela presença de muitos rios, como o Rio Paranaíba e o Rio Grande (IBGE, 2008).

No que se refere à capacidade institucional delimitada pelo ZEE-MG, nota-se que a mesma é composta por indicadores que refletem formas diferenciadas de gestão, podendo ser destacadas as seguintes: Gestão Municipal; Gestão do Desenvolvimento Rural; Gestão Ambiental Municipal e Gestão Cultural, estes não foram explicitamente delineados nesta pesquisa, porém as organizações (secretarias municipais, conselhos municipais, consórcios intermunicipais e comitês de bacias hidrográficas) refletem estes indicadores. Faz-se abaixo breve explicação de cada um dos quatro indicadores.

Ao tratar da Gestão Municipal, observa-se que este tipo de gestão é marcado pelo processo de institucionalização das demandas sociais por meio de políticas públicas e ações governamentais contribuindo para o planejamento e gestão de recursos necessários à prática gerencial, administrativa e financeira de competência do poder público municipal.

A Gestão do Desenvolvimento Rural preza por atender as demandas localizadas no espaço rural tendo os Planos Municipais de Desenvolvimento Rural Sustentável e nos Conselhos de Desenvolvimento Rural Sustentável como instrumentos necessários à prática administrava, direcionada para esta área da esfera municipal.

No que tange à Gestão Ambiental Municipal esta encontra-se atrelada às ações envolvendo secretarias municipais de meio ambiente ou outro tipo de secretaria, como a secretaria de agricultura, envolve ainda a participação de comitês de bacias hidrográficas, consórcios intermunicipais e a presença de órgãos públicos da área ambiental.

Em relação à Gestão Cultural, é notório afirmar que este tipo de gestão deve zelar pelo aparato histórico-cultural de um determinado município ou região, tendo nas ações de órgãos como o Ministério da Cultura, secretarias de cultura, teatros, cinemas, museus, casas de espetáculos, bibliotecas de acervos públicos e demais ações emergidas da comunidade, preocupações que possam fundamentar as políticas públicas direcionadas a este tipo de gestão (ZEE-MG, 2008). 
Referente a esses quatros indicadores os municípios são classificados pelo ZEE-MG (2008), tal não é abordada neste trabalho devido o foco da pesquisa se constituiu nas organizações delimitadas (quadro 2)

\subsubsection{Corpo institucional jurídico}

As organizações jurídicas são aquelas que se organizam de acordo com os princípios e as disposições do direito, de forma legal e lícita. Cidades como Araxá, Campos Altos, Carmo do Paranaíba, Patrocínio, Patos de Minas, São Gotardo, são consideradas as principais comarcas da região, sendo que os municípios debilitados dessa presença judiciária se tornam dependentes da comarca mais próxima.

Em relação à presença de justiça do trabalho e da justiça federal, poucos municípios atendem a esse quesito, como Araxá, Patos de Minas e Patrocínio, sendo esses municípios, os que mais se destacam na região do Alto Paranaíba em todos os aspectos, inclusive, estão entre os municípios com condições muito favoráveis em gerar desenvolvimento sustentável conforme revelado em estudos do Zoneamento Ecológico Econômico de Minas Gerais.

\subsubsection{Organizações Financeiras}

As organizações financeiras podem ser órgãos públicos ou privados, oficialmente autorizados, que lidam com recursos financeiros. Nos 31 municípios pesquisados encontrou-se algum tipo de organização financeira, sendo que pode ser observada a proporcionalidade entre número de habitantes e o número de organizações financeiras. $\mathrm{Na}$ maioria dos municípios há postos de atendimento cooperativo e de Postos de Atendimento Bancário (PAB).

Em se tratando das organizações de microfinanças e atendimento bancário comercial estes somente foram encontradas em municípios da região com maior volume populacional. Em termos gerais Araxá e Patos de Minas são municípios que se destacam pela presença destas organizações.

\subsubsection{Organizações de fiscalização e controle}

As organizações de fiscalização e controle são aquelas que fiscalizam e controlam certas atividades e recursos advindos das esferas municipais, estaduais, federais e também necessidades pessoais.

Nem todos os municípios da região do Alto Paranaíba possuem esse tipo de organização. Por meio da pesquisa realizada foi constatada a presença da receita estadual em municípios como Araxá, Campos Altos, Carmo do Paranaíba, Coromandel, Estrela do Sul, Lagoa Formosa, Monte Carmelo, Patos de Minas, Patrocínio, Rio Paranaíba, Romaria, Sacramento e Ibiá. Já as unidades da receita federal estão presentes apenas em Araxá, Coromandel, Patos de Minas e Patrocínio. Algumas poucas cidades da região possuem unidade de atendimento da previdência social, junta comercial e cartório eleitoral (Araxá, Coromandel, Carmo do Paranaíba e Patos de Minas).

\subsubsection{Aparato institucional de ensino e pesquisa}

As organizações de ensino e pesquisa são aquelas que utilizam de um conjunto de métodos e técnicas para transmitir conhecimentos, objetivando ampliá-los por meio da pesquisa de determinada área do saber.

Através da pesquisa realizada foi possível identificar a presença de organizações de ensino em todos os municípios da região do Alto Paranaíba, desde o ensino fundamental ao ensino médio. Já as organizações de ensino superior estão presentes em 12 dos 31 municípios da região do Alto Paranaíba, sendo que é dado destaque à única instituição de ensino superior público federal da região (Universidade Federal de Viçosa), localizada na cidade de Rio Paranaíba. Conseqüentemente as demais são privadas.

No que se refere às organizações de Pósgraduação Stricto-sensu (mestrado e doutorado), elas se encontram ausentes na Região. Tal constatação deverá começar a ser modificada com a recente implantação, no ano de 2007, da Universidade Federal de Viçosa - Campus Rio Paranaíba. Esta instituição de ensino é tradicional na área de pós-graduação (mestrado e doutorado) no país, principalmente nas áreas das ciências agrárias.

\subsubsection{Organizações de ensino profissionalizantes}

As organizações de ensino profissionalizante são aquelas que além de ensinar e transmitir conhecimentos tem como foco a profissionalização do indivíduo, capacitando-o para atuar no mercado de trabalho. 
As organizações de ensino profissionalizante como, SEBRAE, SENAC, SENAI, SENAT e SENAR possuem escritórios em poucos municípios da região, mas atendem às cidades mais próximas. Apenas Patos de Minas tem escritórios de todas essas organizações do chamado sistema "S". Foi constatado também a existência de dois Centros Federais de Educação Tecnológica (CEFETs), situados em Araxá e Patos de Minas.

Em termos gerais os municípios que se destacam pela presença de organizações de ensino profissionalizantes são Patos de Minas e Araxá.

\subsubsection{Organizações de segurança pública}

As organizações de segurança pública são aquelas que garantem a proteção dos interesses individuais e assegura o pleno exercício da cidadania.

Apenas Araxá e Patos de Minas apresentam simultaneamente batalhão da policia militar e da polícia civil. Em sete municípios da região existe unidade prisional, dentre eles São Gotardo, Carmo do Paranaíba, Patos de Minas e Araxá. Raras são as cidades que possuem guarda municipal ressaltando que o número de pessoas por policial militar e civil varia entre 500 a 2000 pessoas nos municípios que compõem a região do Alto Paranaíba (as que possuíam número inferior a 2000, apresentam o índice como ausente).

Novamente Araxá e Patos de Minas se destacam, já que possuem simultaneamente todas as organizações de segurança pública mapeadas.

\section{Configuração Institucional do Alto Paranaíba}

Nos últimos tempos, as questões ambientais vêm sendo discutidas e recentemente tomaram proporções globais a partir do momento que estas questões se tornaram caso de "política pública". O desequilíbrio entre o crescimento econômico e a preservação ambiental, é o fator determinante para essas discussões e para o levantamento de inúmeros questionamentos, sendo que o objetivo do presente trabalho foi 0 de identificar a capacidade institucional das organizações públicas e privadas da região do Alto Paranaíba na geração de políticas públicas e parcerias voltadas para o desenvolvimento sustentável.

Partindo dessa percepção, foi feito em todos os municípios da região do Alto Paranaíba levantamento quantitativo dos tipos de organizações delimitadas pelo ZEE como, organizações municipais, jurídicas, financeiras, de fiscalização e controle, de ensino e pesquisa, de ensino profissionalizante e de segurança pública, o que possibilitou a identificação por parte dos pesquisadores, dos papéis que estas mesmas organizações exercem no contexto atual. Este levantamento do corpo institucional da região seguindo os critérios do componente institucional do ZEE-MG caracterizou-se como a fase I da pesquisa.

Os resultados evidenciaram que as organizações (ver quadro 2) encontradas nos 31 municípios da região do Alto Paranaíba revelam, de maneira conjunta, em um potencial foco gerador de políticas ambientais de sustentabilidade. Contudo, a simples presença desta rede de organizações não significa a efetiva participação das instituições no processo de identificação, elaboração, implementação e avaliação de políticas ou parcerias direcionadas para a sustentabilidade dos municípios da região. Dentre os 31 municípios pertencentes ao Alto Paranaíba, três deles se destacam pela amplitude institucional que os separa. O primeiro apresenta o maior número de organizações presentes, o segundo, pela sua classificação intermediária e o terceiro município, apresenta deficiência em relação às organizações pesquisadas. Estes municípios são respectivamente, Patos de Minas, Coromandel e Douradoquara (ver quadro 3). Tal classificação se realiza basicamente através das discrepâncias quantitativas existentes entre estes municípios.

Sendo assim, a região do Alto Paranaíba é dotada de potencialidades para o desenvolvimento sustentável, constatado em fatores abrangentes como o econômico e o ecológico, podendo ser convertidos em ações e práticas que poderão corroborar na sustentabilidade da região. Para tanto, o estudo em questão é revelador de novas recomendações e possibilidades que estão contribuindo recentemente para aprofundar as questões ambientais. Entretanto há a necessidade de um estudo mais aprofundado destas instituições o que será realizado na II fase dessa pesquisa que se encontra em desenvolvimento.

A II fase da pesquisa visa pesquisar qualitativamente a existência de relação direta entre a presença de organizações e a geração de políticas públicas e parcerias público-privadas voltadas para a geração de desenvolvimento sustentável. A questão principal é: esta classificação de cunho quantitativo é realmente fidedigna com a realidade dos municípios da região do Alto Paranaíba? Tal questão vai em direção as ressalvas do próprio ZEE-MG, no qual se observa que "a natureza qualitativa das informações que 
caracterizam cada município, deve ser alvo de pesquisas específicas" (ZEE-MG, 2008, p. 194).

\section{Notas}

1. MDA: Ministério do desenvolvimento Agrário, CONDRAF: Conselho Nacional de Desenvolvimento Rural Sustentável.

2. A "potencialidade social" é constituída por quatro componentes: Humano, Institucional, Produtivo e o Natural.

3. Este conceito foi estabelecido pelos autores neste trabalho devido que o município de Coromandel em comparação com o de Patos de Minas apresentar um número de organizações significadamente menor. $\mathrm{Na}$ análise do ZEE-MG (2008) no que concerne ao Componente Institucional Coromandel é caracterizado como "muito favorável".

4. Na classificação do ZEE-MG (2008) Douradoquara é classificado como "pouco favorável".

\section{Referências}

ALENCAR, E. Introdução à metodologia da pesquisa. Lavras: UFLA/FAEPE, 2000.

ALEXANDER, J. C. A importância dos clássicos. In: Teoria social hoje. GIDDENS, A.; TURNER, J. (orgs.). São Paulo: UNESP, 1999.

BOWRING, M. A. De/constructing theory a look at the institucional theory that positivism built. Journal of management inquiry, v. 9, n. 3, September 2000, p. 258-270.

CAVALCANTI, C. Desenvolvimento e natureza: estudos para uma sociedade sustentável. São Paulo: Cortez, 1995

EHLERS, E. M. Agricultura sustentável: origens e perspectivas de um novo paradigma. 2. ed. Guaíba: Agropecuária, 1999.

FERREIRA, L. da C.; FERREIRA L. da C. Limites ecossistêmicos: novos dilemas e desafios para o Estado e para a sociedade. In HOGAN, D. J.; VIEIRA, P. F. (Orgs.). Dilemas socioambientais e desenvolvimento sustentável. 2. ed. Campinas: Ed. da UNICAMP, 1995.

GIL, A. C. Métodos e técnicas de pesquisa social. 5. ed. São Paulo: Atlas, 2007.

LAVILLE, C.; DIONNE, J. A construção do saber: manual de metodologia da pesquisa em ciências humanas. Porto Alegre: Artes Médicas; Belo Horizonte: UFMG, 1999.
LIMA, F. R., RIBEIRO, A. G. Alternativas sustentáveis para a redução da vulnerabilidade socioeconômica e ambiental da agricultura familiar na região do cerrado mineiro: os casos de Uberlândia e Patrocínio. In: II Simpósio Regional de Geografia: "Perspectivas para o Cerrado no Século XXI", Uberlândia, 2003.

MACHADO-DA-SILVA, C.; GONÇALVES S. A. Mudança organizacional, esquemas interpretativos e contexto institucional: dois casos ilustrativos.

Revista de estudos organizacionais. Maringá, v. 1, n. 2, p. 1-16, jul. 2000.

MARCONI, M. A.; LAKATOS, E. V. Fundamentos de metodologia científica. 5. ed. São Paulo: Atlas, 2003.

\section{MDA/CONDRAF. Diretrizes para o}

desenvolvimento sustentável. Ministério do desenvolvimento agrário. DF: Brasília, 2006.

$\mathrm{PECl}, \mathrm{A}$. A nova teoria institucional em estudos organizacionais: uma abordagem crítica. IN: Anais do XXIX Enanpad, 2005, Brasília, DF, 18-21 Setembro.

SACHS, I. Desenvolvimento includente, sustentável, sustentado. Rio de Janeiro: Garamond, 2004.

SILVA, L. L. O papel do Estado no processo de ocupação das áreas de cerrado entre as décadas de 60 e 80. Uberlândia: Caminhos de geografia Revista On-Line, 1(2), p. 24-36, dez./2000.

SILVA, C. L. da; MENDES, J. T. G. Reflexões sobre o desenvolvimento sustentável: agentes e interações sob a ótica multidisciplinar. Petrópolis: Vozes, 2005.

TOLBERT, P. S., ZUCKER, L. G. A institucionalização da teoria institucional. In: Handbook de estudos organizacionais: modelos de análise e novas questões em estudos organizacionais. v. 1. p. 194-217. São Paulo: Atlas, 2006.

VASCONCELOS, V. F., SANTOS, R. J. dos. A chegada do projeto PRODECER-I em Iraí de Minas e os migrantes. In: II Simpósio Regional de Geografia: "Perspectivas para o Cerrado no Século XXI", Uberlândia, 2003.

VIOLA, E. J.; LEIS, H. R. A evolução das políticas ambientais no Brasil, 1971-1991: do bissetorialismo preservacionista para o multissetorialismo orientado para o desenvolvimento sustentável. In HOGAN, D. J.; VIEIRA, P. F. (Orgs.). Dilemas socioambientais e desenvolvimento sustentável. 2. ed. Campinas: UNICAMP, 1995. 
ZONEAMENTO ECOLÓGICO-ECONÔMICO DO

BAIXO RIO PARANAÍBA: Subsídios técnicos.

Relatório Final. Brasília: MMA/SDS, 2002.

ZONEAMENTO ECOLÓGICO-ECONÔMICO DO

ESTADO DE MINAS GERAIS (ZEE-MG).

Relatório. Lavras: Editora UFLA, 2008. 